\title{
CONVENTIONAL VS PREFABRICATED BUILDINGS: PURSUING THE GOAL OF SUSTAINABILITY
}

\author{
DOI: 10.18485/arh_pt.2020.7.ch34
}

\section{_ Katerina Tsikaloudaki}

Aristotle University of Thessaloniki, Civil Engineering

Dep., Thessaloniki, Greece, katgt@civil.auth.gr

\section{- Theodore Theodosiou}

Aristotle University of Thessaloniki, Civil Engineering

Dep., Thessaloniki, Greece, katgt@civil.auth.gr

\section{_ Stella Tsoka}

Aristotle University of Thessaloniki, Civil Engineering Dep., Thessaloniki, Greece, katgt@civil.auth.gr

\section{_ Panagiotis Chastas \\ Aristotle University of Thessaloniki, Civil Engineering \\ Dep., Thessaloniki, Greece, katgt@civil.auth.gr}

\begin{abstract}
In Greece, and many other European countries, the majority of buildings are made of a reinforced concrete bearing structure, erected in situ, and brick masonry. On the other hand, prefabricated buildings consist of factory-made components that are transported and assembled on-site to form the complete structure. Both building construction types have advantages and disadvantages, and both can be optimised in order to reach advanced performance levels. This paper attempts to highlight the main differences that are found between conventional and prefabricated buildings mainly in the field of sustainability. More specifically, a model of a small single family house is used in order to study the energy and environmental performance, when the two construction types are employed: the conventional one, composing of reinforced concrete and brickwork, and the prefabricated one, using the building module that was developed within the research project SU.PR.I.M. For both construction types, the heating and cooling energy needs are calculated for different thermal insulation thicknesses and climate contexts, in order to show which construction is more energy efficient. Furthermore, the environmental impact of both constructions is estimated, with the aim to highlight the overall performance of each building not only during its use, but throughout their lifetime. Through this analysis the potential of both construction types to form a sustainable building is explored, showing interesting results and new insights for the building industry and the prospective users.
\end{abstract}

KEYWORDS _ prefabricated buildings, energy and environmental performance, sustainability

\section{INTRODUCTION}

The building sector contributes significantly to the final energy consumption both at a European and at a national level. In 2019 this share was approximately equal to $41 \%$ for the EU-28 and Greece, taking into account both the residential and the services sectors (EU, 2019). When only residential 
buildings are concerned, the share of consumed energy is equal to $27.2 \%$ for EU-28 and concerns mainly gas (36\%) and electricity (24\%). In Greece the residential buildings are responsible for the $27.5 \%$ of the final energy consumption, with electricity $(40 \%)$ and oil $(30 \%)$ being the principal fuels (CRES, 2018). In general, the total GHG per capita is $9.2 \mathrm{t} \mathrm{CO2} \mathrm{eq/cap} \mathrm{for} \mathrm{Greece,} \mathrm{while} \mathrm{the} \mathrm{average}$ for the EU-28 is 8.8 t CO2 eq/cap (EU, 2019).

The vast majority of buildings in Greece are dwellings (79\%) and most of them have been built before 1980 , when no provisions for energy performance were established. The dominant material for the buildings' bearing structure is reinforced concrete; and for the walls the brick masonry. Prefabricated buildings, the basic forms of which are made of wood, steel or concrete, account for only $2 \%$ of the total building stock in Greece, while the average share in Europe is $15 \%$ and the rate is growing. The low penetration of prefabricated buildings in the building industry is not only met in Greece but it is common to the Mediterranean countries (Apaydin,2011). For many years, prefabricated buildings were regarded as of inferior quality or designated for temporary constructions. But today, things have changed; prefabricated buildings compete the conventional ones in every aspect of performance, i.e. structural, energy, hygrothermal, acoustic, fire, environmental, etc.

Within this framework, the research project SU.PR.I.M. (SUstainable PReconstructed Innovative Module) aims at the development of an innovative building module with advanced properties that will act as a vertical wall element in prefabricated residential buildings. This new building module will satisfy high requirements for its operation and performance. Specifically, it will be able to bear and deliver safely all the imposed building loads; display advanced energy performance; demonstrate excellent hygrothermal behavior; provide acoustic insulation protection and resistance against fire actions; minimize its environmental footprint during its life cycle.

In this paper, the energy and the environmental performance of a small one-family building, constructed with the new SU.PR.I.M. module, is analyzed and compared with the one derived for the conventional building construction form.

\section{METHODOLOGY}

The study concerns a small one-family building, presented in Figure 1. It has one storey and covers an area of $47.32 \mathrm{~m}^{2}$. The plan is rectangular, expanded along the south-north axis, with openings only on the south and north walls. The roof is inclined and is covered with clay tiles. Below the inclined roof of the building, there is a horizontal slab, made of reinforced concrete, above which a thick layer of $10.0 \mathrm{~cm}$ of thermal insulation (XPS) is positioned. The floor of the house, in contact with the ground, is constructed with reinforced concrete and is insulated with a $10 \mathrm{~cm}$ thick XPS layer. The windows comprise of PVC frame with a double, low-e glazing. The U-value of the transparent elements is equal to $2 \mathrm{~W} /\left(\mathrm{m}^{2} \mathrm{~K}\right)$.

The building is examined for two different configurations of the vertical elements:

a) a conventional wall, composed of bearing masonry made of hollow clay bricks, as a representative of the conventional construction, and

b) the new module developed through the SU.PR.I.M. project, as a representative of the prefabricated building alternative.

The prefabricated building element has the form of a composite panel. It consists of two lightly reinforced concrete plates, $5 \mathrm{~cm}$ thick each, which are positioned on either side of vertical (and occasionally diagonal) metal hollow elements. The distance between the vertical hollow metal elements is about $0.70 \mathrm{~m}-1.00 \mathrm{~m}$ and the gap is filled in with a thermal insulation material, usually expanded or extruded polystyrene. The prefabricated panels are connected to each other and to the metal columns/beams of the structural organization with anchors, especially designed for this construction. The energy performance of both building alternatives was assessed with EnergyPlus, a dynamic simulation software, that is commonly used for such purposes. The energy analysis concerned the annual heating and cooling needs of the buildings for different scenarios, which involved:

a) the thickness of external thermal insulation, which was assumed to be the same in the 
two wall alternatives and equal to $5 \mathrm{~cm}, 10 \mathrm{~cm}, 15 \mathrm{~cm}$ and $20 \mathrm{~cm}$ of XPS

b) the climate conditions. It was assumed that the two examined building types are located at 4 different cities in Greece with respect to the four climatic zones defined in the country: Heraklion (Lat. $35^{\circ} 19^{\prime} \mathrm{N}$; Long. $25^{\circ} 08^{\prime} \mathrm{E}$ ) for zone A -the warmest-, Athens (Lat. $37^{\circ} 58^{\prime} \mathrm{N}$; Long. $23^{\circ} 42^{\prime} \mathrm{E}$ ) for zone B, Thessaloniki (Lat. $3740^{\circ} 38^{\prime} \mathrm{N}$; Long. $22^{\circ} 56^{\prime} \mathrm{E}$ ) for zone $\mathrm{C}$ and Grevena (Lat. $40^{\circ} 05^{\prime} \mathrm{N}$; Long. $21^{\circ} 25^{\prime} \mathrm{E}$ ) for zone $\mathrm{D}$-the coldest-.

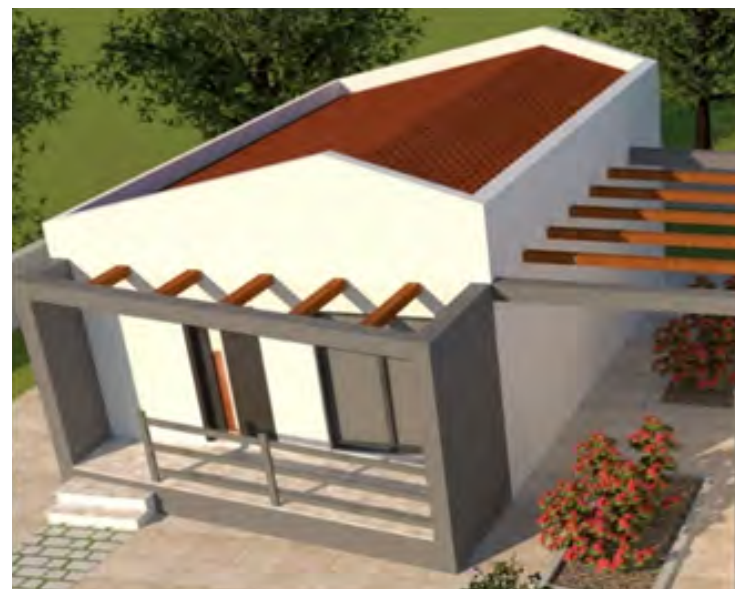

_. Figure 1: External 3D view and plot of the examined house.

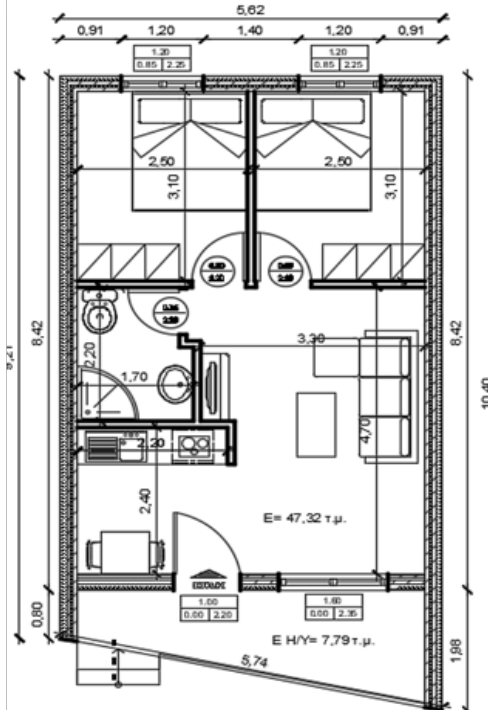

In terms of the operational schedules of the house, involving occupancy, lighting, equipment, heating and cooling setpoints and infiltration rates, they have been set according to the respective values provided by the Technical Guides of the recast of the Hellenic Building Energy Performance Regulation. Furthermore, in order to simulate in a more realistic way the performance of the building during summer, it has been considered that the occupants will naturally ventilate the building during the cooling period, provided that the outdoor air temperature is lower than the indoor one by at least $1.0^{\circ} \mathrm{C}$. The simulations were conducted on an annual basis and the ideal load HVAC system has been employed in the model. The Domestic Hot Water (DHW) needs were also calculated, for all climatic zones of Greece, according to the Hellenic Regulation for Building Energy Performance, EN 15316-3.2 and EN 15316-3.3.

The environmental assessment follows the energy performance analysis and examines the two building types for the four different scenarios of external thermal insulation thicknesses (XPS: $5 \mathrm{~cm}$, $10 \mathrm{~cm}, 15 \mathrm{~cm}$ and $20 \mathrm{~cm}$ ) and the four climate zones of Greece (A, B, C and D).

Life cycle assessment follows the principles of ISO 14040, ISO 14044, EN 15804 and EN 15978; and calculates the environmental impact for the whole building life cycle, for all processes within the system boundaries (Figure 2). The LCl data derive from the Ecoinvent database while every other necessary information and input data (quantities and properties of material/components, transportation distances) come from the building construction plans, the Greek market and from personal communication with the module manufacturer; and when combined they provide the environmental impact for all the upstream (A1, A2, A3, Figure 2) and core (A4, A5, Figure 2) processes of the two analysed buildings.

The replacement phase (B4, Figure 2) relates to the reference service life considered for each material/component that comes from the international literature, ISO 15686-8 and EN 15459. For the quantification of the operating impact (energy use phase, B6, Figure 2), the life cycle assessment transforms the results of the energy performance analysis (heating, cooling and domestic hot water needs) of the two building configurations into consumptions, by considering the use of a gas boiler 
for heating and domestic hot water; and an air-to-air heat pump for cooling. The end-of-life scenario relates to the demolition/deconstruction ( $\mathrm{C} 1$, Figure 2 ) of the building with a hydraulic digger and the transportation ( $C 2$, Figure 2$)$ of the $C \& D$ waste to the nearest management facility $(50 \mathrm{~km}$ from the construction site); and takes no further consideration of the waste management procedures due to the lack of available or reliable data for the Greek region. Finally, the environmental impact is calculated per square meter of reference/heated building area, for 50 years building lifespan and for the impact indicators of methods CML-IA Baseline and Cumulative Energy Demand; following the principles of Product Category Rule (PCR) 2014:02 for buildings through the Environmental Product Declaration (EPD) system.

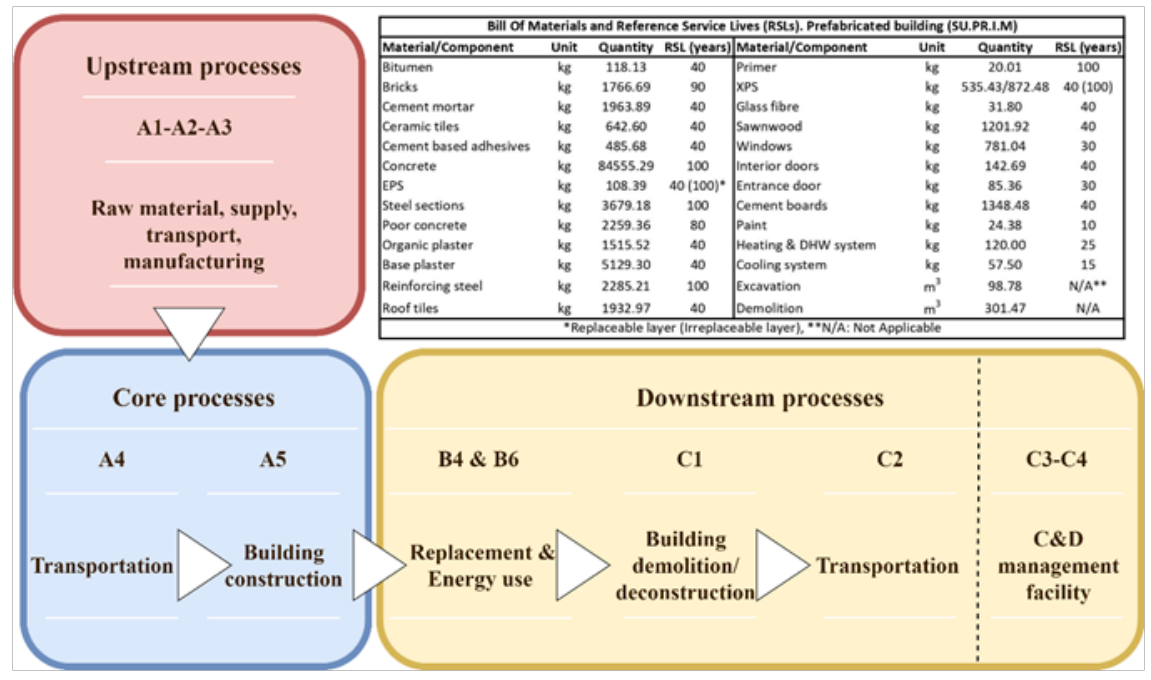

_ Figure 2: System boundaries and life cycle processes for the two building configurations. Bill of materials for the analysed prefabricated building (SU.PR.I.M.).

\section{THE ENERGY PERFORMANCE ANALYSIS}

In Figures 3-4 the annual heating and cooling needs are plotted for every climatic zone separately. The total energy needs range from ca. $20 \mathrm{kWh} / \mathrm{m} 2$ to ca. $60 \mathrm{kWh} / \mathrm{m} 2$ with respect to the climate context. In the warmest climate zone, Zone A, the energy required for covering the heating and the cooling needs are always higher for the conventional construction (Figure 3.a). The difference ranges between $2 \%$ and $15 \%$ with respect to the thermal insulation thickness; it is interesting to notice that as the thickness of the thermal insulation increases, the difference in energy needs between the two wall configurations becomes lower. In Zone A, the cooling needs are significantly higher than the heating ones. In fact, the cooling needs can be even 4 times higher than the heating ones. The gap becomes larger as the thermal insulation thickness increases. This can be attributed to the fact that the maximization of thermal resistance of the walls leads to the minimization of heat losses during winter, but it does not cause an equivalent decrease of the cooling needs, as the solar heat gains, its major component, stem mainly from the transparent building elements. For the same reason, maximum differences between the cooling needs for the two construction types hardly exceeds $6 \%$, while for the heating loads the maximum difference reaches $29 \%$. Again, the difference on the heating needs between the two examined construction types is not the same for every thickness of thermal insulation. As the thermal insulation thickness increases, its impact on heating load reduction weakens.

Similar trends are observed when the buildings are located in Zone B (Figure 3.b). Again, the energy 
needs are lower for the building that integrates the SUPRIM element, but the differences range in lower levels, i.e. between $2 \%$ and $12 \%$. The higher differences are observed for the heating loads ( $4.5 \%$ to $24 \%$ with regard to the thermal insulation thickness), while the difference in cooling needs are low ( $1.3 \%$ to $4.7 \%)$, although the cooling needs are almost doubled.

The energy needs profile changes drastically when the buildings are located in a colder location, such as Thessaloniki in zone C (Figure 4.a). The amount of energy needs increases significantly, and the heating needs prevail, as they are almost double with respect to the cooling ones. Again, the building constructed with the SU.PR.I.M. wall elements perform better than the conventional one, as its energy needs are always lower. The difference on total energy needs ranges between $3 \%$ and $15 \%$, with the heating loads being reduced by $3 \%$ to $17.5 \%$ with respect to the thickness of thermal insulation. In zone $\mathrm{D}$, the coldest of Greece, the energy needs reach their highest levels, with the cooling loads accounting for only $1 / 3$ of the heating ones (Figure 4.b). The performance of the SU.PR.I.M. wall elements is better in the colder climate of zone $D$, as the decrease on the energy needs ranges from $3 \%$ to $14 \%$. Again, the heating reduction is more substantial, reaching $16 \%$.

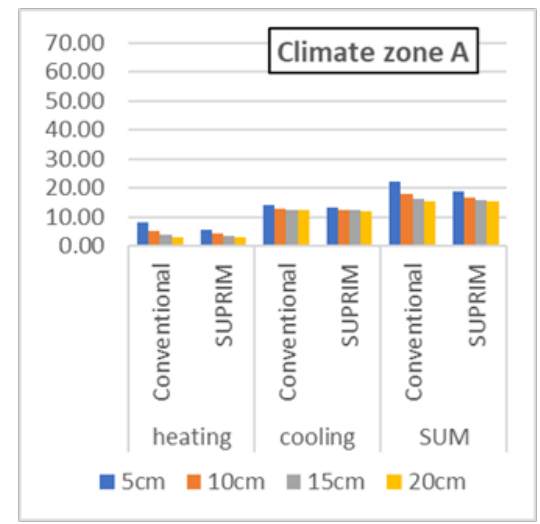

a.

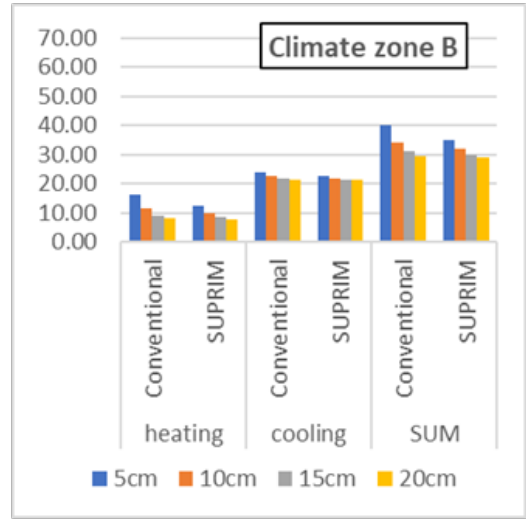

b.

_ Figure 3: The heating, cooling and total energy needs for the two wall configurations and different thicknesses of thermal insulation, under the climatic conditions of the warmest climate zones, zone $\mathrm{A}$ and zone $\mathrm{B}$.

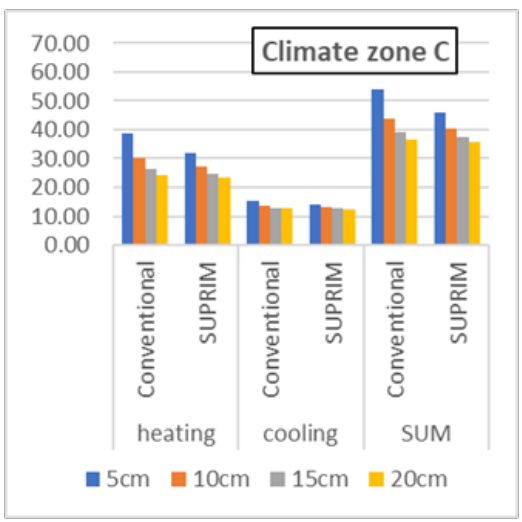

a.

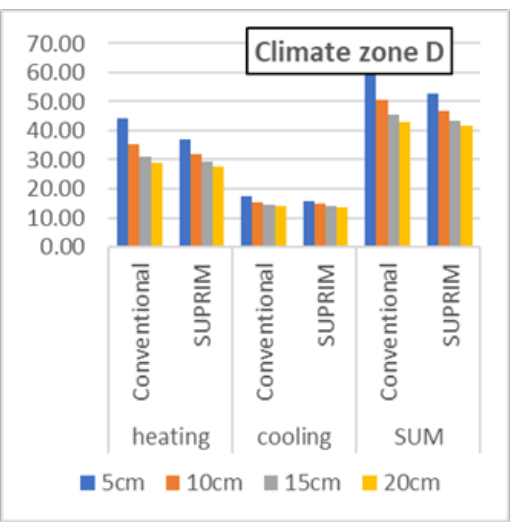

b.

_ Figure 4: The heating, cooling and total energy needs for the two wall configurations and different thicknesses of thermal insulation, under the climatic conditions of the coldest climate zones, zone $\mathrm{C}$ and zone $\mathrm{D}$. 
Considering the domestic hot water and the calculational approach, the respective needs for both building configurations are $34.67 \mathrm{kWh} / \mathrm{m} 2 \cdot$ year, $36.98 \mathrm{kWh} / \mathrm{m} 2 \cdot$ year, $39.85 \mathrm{kWh} / \mathrm{m} 2 \cdot$ year and 42.52 $\mathrm{kWh} / \mathrm{m} 2 \cdot$ year for zones $\mathrm{A}, \mathrm{B}, \mathrm{C}$ and $\mathrm{D}$ respectively.

\section{THE ENVIRONMENTAL PERFORMANCE ANALYSIS}

The contribution of each life cycle process to the total life cycle impact of the analysed buildings varies between the impact categories (Figure 5). For the prefabricated building and the base case scenario (XPS insulation thickness $10 \mathrm{~cm}$, climate zone $\mathrm{C}$ ), the average impact contribution (including all indicators) for the upstream processes (A1-A3) is calculated at $36.6 \%$, while the core processes (A4-A5) contribute with an average of $0.5 \%$ to its total life cycle impact. The replacement process (B4) of materials/components correlates with an important average share of $28.5 \%$, while the operating phase (B6) with a total of $33.9 \%$ (heating $9.5 \%$, cooling $10.1 \%$, DHW $14.3 \%$ ). Finally, the downstream processes (end-of-life, $\mathrm{Cl}$ and $\mathrm{C} 2$, Figure 2) relate only to $0.5 \%$ share of the life cycle impact, which correlates with the exclusion of the waste management processes (C3, C4) from the system boundaries due to the lack of available/reliable data for the Greek region. The conventional building analysis relates to $34.8 \%$ average share for the upstream processes, $34.7 \%$ for the operating phase (B6: heating $10.2 \%$, cooling $10.7 \%$, DHW $13.8 \%$ ), $28.5 \%$ for the replacement process and $0.5 \%$ for the end-of-life processes. It must be noted that for the core processes (A4-A5) the contribution increases by $+0.5 \%(1.0 \%)$ in reference to the prefabricated building and reflects the increased share of the in-situ building construction processes.

\section{SU.PR.I.M.}

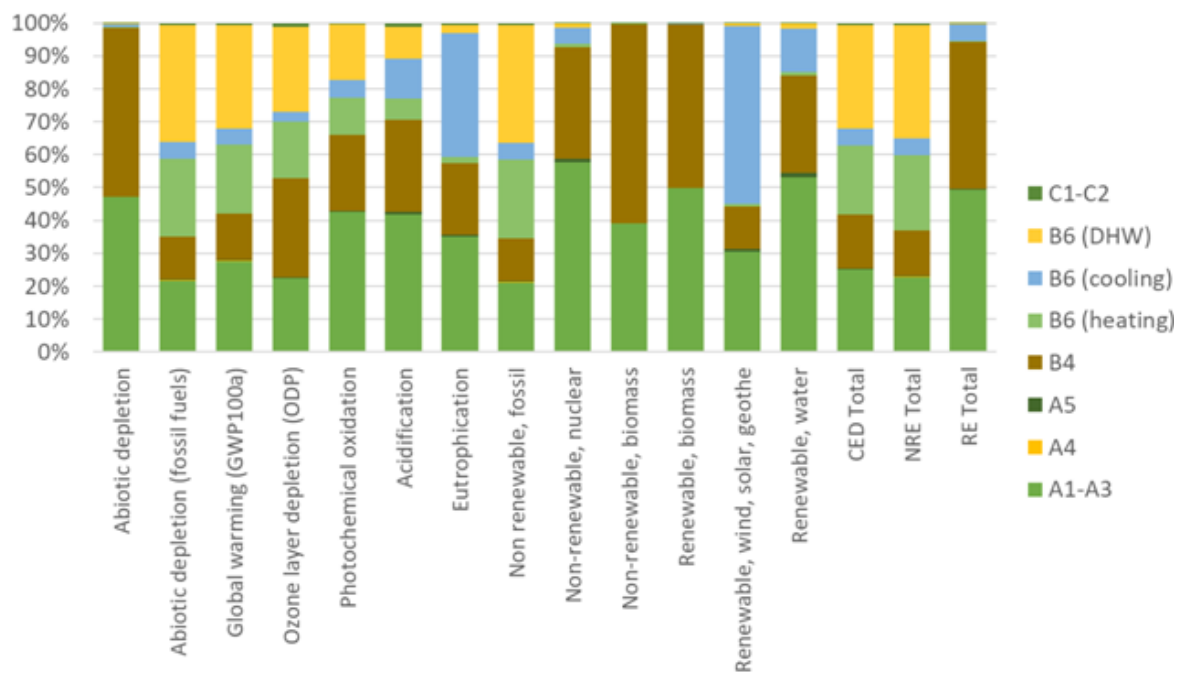

_ Figure 5: Life cycle impact of the prefabricated building (SU.PR.I.M.) per impact category and life cycle process within the system boundaries (base case scenario: XPS $10 \mathrm{~cm}$ scenario and climate zone $\mathrm{C}$ of Greece).

Considering only the embodied impact (Figure 6.a), the results for both the prefabricated and the conventional building highlight the increased average contribution for the PVC windows $(12.04 \%$ and $12.43 \%$ respectively), the heating/DHW system ( $8.81 \%$ and $9.18 \%$ respectively), the XPS insulation $(7.78 \%$ and $7.93 \%$ respectively) and the cooling system ( $7.29 \%$ and $7.21 \%$ respectively). Besides those, the main contributors in terms of embodied impact are the steel sections (11.63\%) for the prefabricated building and the bricks $(10.50 \%)$ for the conventional one. The impact indicators glob- 
al warming potential, abiotic depletion (fossil fuels), ozone layer depletion, non-renewable fossil, renewable biomass, NRE total and CED Total, indicate lower embodied impact for the prefabricated building in reference to the conventional one, for the base case scenario (Figure 6.b). The remaining indicators reflect the higher embodied impact of the prefabricated building which relates mostly to the use of steel sections and primer for their protection from oxidation during their useful service life; and secondly to the use of an additional layer of expanded polystyrene (EPS) in the prefabricated walls' core.
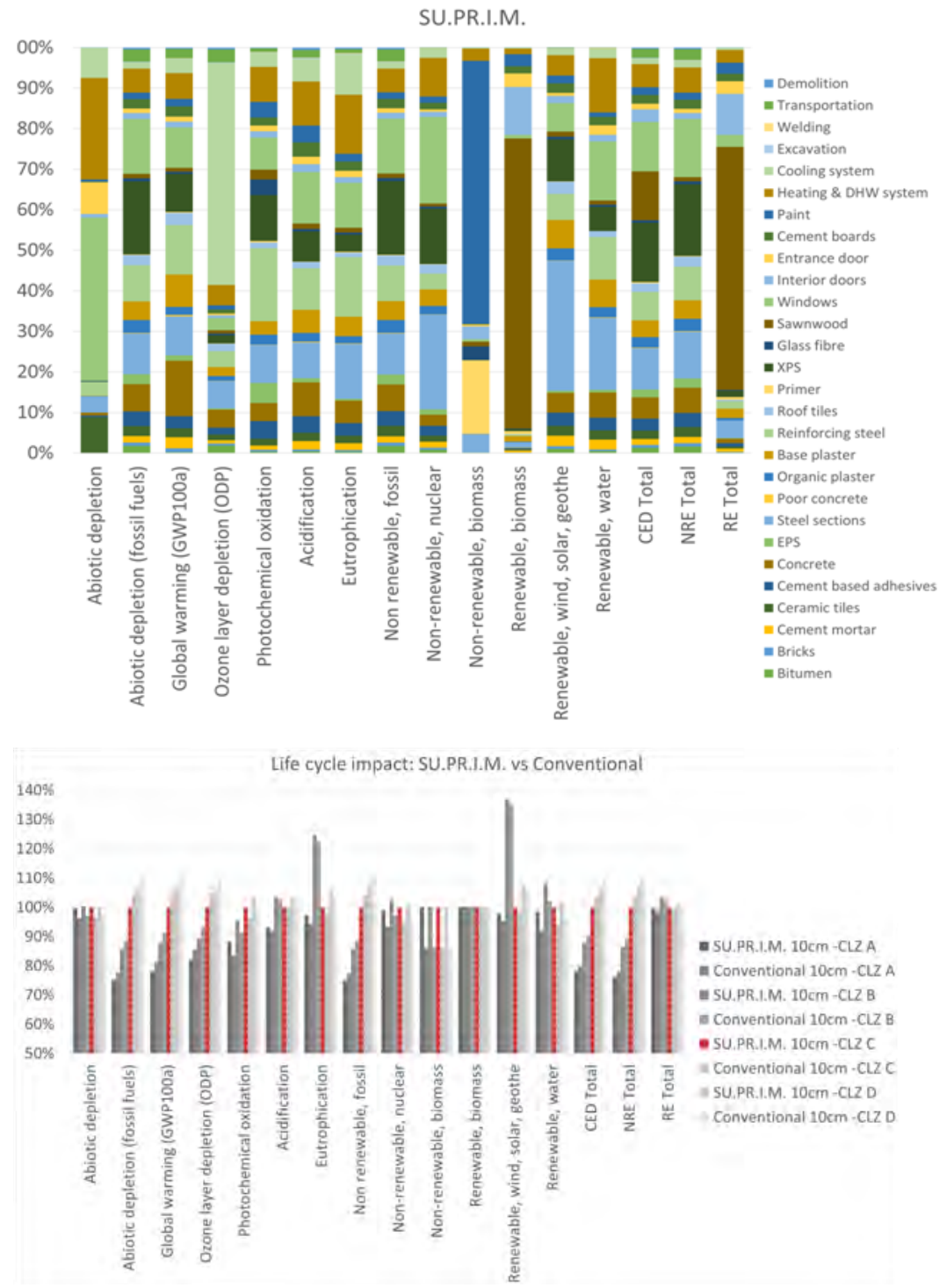

_- Figure 6:

a. Percentage contribution of each material/component/process to the embodied impact of the prefabricated building (SU.PR.I.M.) per impact category (base case scenario: XPS $10 \mathrm{~cm}$, climate zone C of Greece).

b. Comparative analysis of the two buildings. All Climate Zones (CLZ: A, B, C, D of Greece; base case scenario: XPS $10 \mathrm{~cm}$, climate zone $\mathrm{C}$ of Greece, red coloured hatch pattern in diagram b). 
Finally, the life cycle impact follows the climate dependency of results, as indicated by the energy performance analysis for both building configurations. If we consider the two most common environmental indicators for buildings, emissions and energy, that same dependency correlates with an average increase in the life cycle emissions for the prefabricated building of $12.1 \%$ for zone $B, 27.6 \%$ for zone $C$ and $33.6 \%$ for zone $D$; and in its life cycle energy of $12.3 \%$ for zone $B, 27.5 \%$ for zone $C$ and $31.9 \%$ for zone $D$, in reference to zone $A$, respectively.

\section{CONCLUSIONS}

The analysis showed that the building configured with the new, preconstructed element performed better than the conventional one. The reduction in energy needs reached $15 \%$ in most climate zones, but the decrease in heating demand is much more substantial, as in some cases it exceeded $25 \%$. Life cycle assessment reflects the climate dependency of the results that the energy performance analysis highlights and indicates increase in the life cycle emissions and energy of about $12.1 \%$ $12.3 \%, 27.5 \%-27.6 \%$ and $31.9 \%-33.6 \%$, from climate zone A, to zones B, C and D of Greece respectively. Considering the life cycle balance, the upstream processes (A1-A3), the energy use phase (B6) and the replacement process (B4), contribute with about $1 / 3$ each in the share of the life cycle energy and emissions of the two analysed buildings. The windows, the heating and cooling system and the XPS insulation contribute with important shares in the embodied impact of both building configurations, while the steel sections and the bricks dominate in the prefabricated and the conventional building, respectively. Finally, even though the prefabricated building presents better environmental performance when compared to the conventional one -among others- in terms of emissions and energy, the results indicate the potential of further improvement in impact indicators such as Eutrophication, where the use of steel sections dominates the building's environmental burden.

\section{ACKNOWLEDGEMENTS}

This research has been co-financed by the European Regional Development Fund of the European Union and Greek national funds through the Operational Program Competitiveness, Entrepreneurship and Innovation, under the call RESEARCH - CREATE - INNOVATE (project code:T1EDK-03042).

\section{REFERENCES}

_ Apaydin, Fahri. 2011. "Effectiveness of prefabricated house industry's marketing activities and Turkish consumers' buying intentions towards prefabricated house". Asian Social Science 7: 267-276.

- CRES-Centre for Renewable Energy Sources. 2018. "Energy efficiency trends and policies in Greece".

_ European Commission. 2019. "EU energy in figures. Statistical pocketbook". 